University of Nebraska - Lincoln

DigitalCommons@University of Nebraska - Lincoln

2008

\title{
First Administration to Humans of a Monoclonal Antibody Cocktail Against Rabies Virus: Safety, Tolerability, and Neutralizing Activity
}

\author{
A.B.H. Bakker \\ Crucell Holland BV, Leiden, The Netherlands \\ C. Python \\ Crucell, Berna Biotech Ltd., Bern, Switzerland \\ C.J. Kissling \\ MDS Pharma Services, Lincoln, NE, USA \\ P. Pandya \\ RelClin, Reliance Clinical Pharmacology and Pharmacokinetic Facility, Dhirubhai Ambani Life Sciences \\ Centre, Navi Mumbai, India \\ W.E. Marissen \\ Crucell Holland BV, Leiden, The Netherlands \\ See next page for additional authors \\ Follow this and additional works at: https://digitalcommons.unl.edu/publichealthresources \\ Part of the Public Health Commons
}

Bakker, A.B.H.; Python, C.; Kissling, C.J.; Pandya, P.; Marissen, W.E.; Brink, M.F.; Lagerwerf, F.; Worst, S.; van Corven, E.; Kostense, S.; Hartmann, K.; Weverling, G.J.; Uytdehaag, F.; Herzog, C.; Briggs, D.J.; Rupprecht, C.E.; Grimaldi, R.; and Goudsmit, J., "First Administration to Humans of a Monoclonal Antibody Cocktail Against Rabies Virus: Safety, Tolerability, and Neutralizing Activity" (2008). Public Health Resources. 15. https://digitalcommons.unl.edu/publichealthresources/15

This Article is brought to you for free and open access by the Public Health Resources at DigitalCommons@University of Nebraska - Lincoln. It has been accepted for inclusion in Public Health Resources by an authorized administrator of DigitalCommons@University of Nebraska - Lincoln. 


\section{Authors}

A.B.H. Bakker, C. Python, C.J. Kissling, P. Pandya, W.E. Marissen, M.F. Brink, F. Lagerwerf, S. Worst, E. van Corven, S. Kostense, K. Hartmann, G.J. Weverling, F. Uytdehaag, C. Herzog, D.J. Briggs, C.E. Rupprecht, R. Grimaldi, and J. Goudsmit 


\title{
First administration to humans of a monoclonal antibody cocktail against rabies virus: Safety, tolerability, and neutralizing activity
}

\author{
A.B.H. Bakker ${ }^{\mathrm{a}, *}$, C. Python ${ }^{\mathrm{b}}$, C.J. Kissling ${ }^{\mathrm{c}}$, P. Pandya ${ }^{\mathrm{d}}$, W.E. Marissen ${ }^{\mathrm{a}}$, M.F. Brink ${ }^{\mathrm{a}}$, \\ F. Lagerwerf ${ }^{a}$, S. Worst ${ }^{a}$, E. van Corven ${ }^{a}$, S. Kostense ${ }^{\mathrm{a}}$, K. Hartmann ${ }^{\mathrm{b}}$, G.J. Weverling ${ }^{\mathrm{a}}$, \\ F. Uytdehaag ${ }^{\text {a }}$, C. Herzog ${ }^{\text {b }}$, D.J. Briggs ${ }^{\text {e }}$, C.E. Rupprecht ${ }^{f}$, R. Grimaldi ${ }^{a}$, J. Goudsmit ${ }^{a}$ \\ a Crucell Holland BV, Leiden, The Netherlands \\ b Crucell, Berna Biotech Ltd., Bern, Switzerland \\ ${ }^{c}$ MDS Pharma Services, Lincoln, NE, USA \\ ${ }^{\mathrm{d}}$ RelClin, Reliance Clinical Pharmacology and Pharmacokinetic Facility, Dhirubhai Ambani Life Sciences Centre, Navi Mumbai, India \\ e College of Veterinary Medicine, Kansas State University, Manhattan, KS, USA \\ ${ }^{\mathrm{f}}$ Rabies Section, Division of Viral and Rickettsial Diseases, Centers for Disease Control and Prevention, Atlanta, GA, USA
}

\section{A R T I C L E I N F O}

\section{Article history:}

Received 13 June 2008

Received in revised form 22 July 2008

Accepted 31 August 2008

Available online 17 September 2008

\section{Keywords:}

Vaccination

Rabies

Post-exposure prophylaxis

Monoclonal antibodies

Unmet medical need

Human rabies immunoglobulin (HRIG)

Equine rabies immunoglobulin (ERIG)

\begin{abstract}
A B S T R A C T
Immediate passive immune prophylaxis as part of rabies post-exposure prophylaxis (PEP) often cannot be provided due to limited availability of human or equine rabies immunoglobulin (HRIG and ERIG, respectively). We report first clinical data from two phase I studies evaluating a monoclonal antibody cocktail CL184 against rabies.

The studies included healthy adult subjects in the USA and India and involved two parts. First, subjects received a single intramuscular dose of CL184 or placebo in a double blind, randomized, dose-escalation trial. Second, open-label CL184 (20 IU $/ \mathrm{kg}$ ) was co-administered with rabies vaccine. Safety was the primary objective and rabies virus neutralizing activity (RVNA) was investigated as efficacy parameter.

Pain at the CL184 injection site was reported by less than $40 \%$ of subjects; no fever or local induration, redness or swelling was observed. RVNA was detectable from day 1 to day 21 after a single dose of CL184 20 or $40 \mathrm{IU} / \mathrm{kg}$. All subjects had adequate $(>0.5 \mathrm{IU} / \mathrm{mL})$ RVNA levels from day 14 onwards when combined with rabies vaccine. CL184 appears promising as an alternative to RIG in PEP.
\end{abstract}

\section{Introduction}

Rabies occurs worldwide and more than 3 billion people live in areas in which the disease is enzootic. Especially children are at risk of infection. Every year about 55,000 people die from rabies, more than $50 \%$ of these in Asia [1,2].

Once clinical symptoms develop, rabies is almost invariably fatal [3]. However, rabies is preventable: even in case of severe rabies exposure (category III according to World Health Organization guidelines), post-exposure prophylaxis (PEP) consisting of thorough wound cleansing and immediate administration of rabies immune globulin (RIG) together with a full course of rabies vaccination is highly effective [4,5].

\footnotetext{
* Corresponding author at: Crucell Holland BV, P.O. Box 2048, 2301 CA Leiden, The Netherlands.

E-mail address: lex.bakker@crucell.com (A.B.H. Bakker).
}

The success of PEP largely depends on an educated population and on the supply of modern RIGs and rabies vaccines [2]. The availability of high-quality biologicals is still low in developing countries and many patients die because PEP is not administered at all or because no RIG is administered [6,7].

The administration of RIG as soon as possible after exposure is essential to inhibit viral spread in the interval before sufficient immunity is developed in response to vaccination [1,3]. Currently, human (HRIG) and equine (ERIG) immune globulins are used. These plasma-derived, polyclonal products are obtained from rabiesvaccinated human donors or horses and can only be produced in limited amounts. Therefore, the WHO strongly encourages the development of alternatives [1,8].

We have developed a human monoclonal antibody (mAb) cocktail, CL184, which consists of two mAbs (CR57, human IgG1 lambda and CR4098, human IgG1 kappa). These mAbs, produced on the PER.C6 ${ }^{\circledR}$ human cell line, are directed against distinct, non-overlapping rabies virus epitopes and do not compete for binding to rabies glycoprotein $[9,10]$. CL184 has demonstrated broad 
Table 1

Demographic characteristics

\begin{tabular}{|c|c|c|c|c|c|c|}
\hline RAB-M-A001 & & Placebo $(N=11)$ & CL184 $8 \mathrm{IU} / \mathrm{kg}(N=12)$ & CL184 $20 \mathrm{IU} / \mathrm{kg}(N=11)$ & CL184 $40 \mathrm{IU} / \mathrm{kg}(N=12)$ & $\begin{array}{l}\text { CL184 } 20 \mathrm{IU} / \mathrm{kg}+ \\
\operatorname{PCECV}(N=11)\end{array}$ \\
\hline $\operatorname{Sex}(n(\%))$ & $\begin{array}{l}\text { Female } \\
\text { Male }\end{array}$ & $\begin{array}{l}4(36) \\
7(64)\end{array}$ & $\begin{array}{l}6(50) \\
6(50)\end{array}$ & $\begin{array}{l}3(27) \\
8(73)\end{array}$ & $\begin{array}{l}5(42) \\
7(58)\end{array}$ & $\begin{array}{l}7(64) \\
4(36)\end{array}$ \\
\hline Race $(n(\%))$ & $\begin{array}{l}\text { Asian } \\
\text { Black } \\
\text { Caucasian } \\
\text { European/Middle Eastern } \\
\text { Hispanic } \\
\text { Mixed }\end{array}$ & $\begin{array}{l}0 \\
1(9) \\
9(82) \\
0 \\
1(9) \\
0\end{array}$ & $\begin{array}{l}0 \\
0 \\
11(92) \\
0 \\
1(8) \\
0\end{array}$ & $\begin{array}{l}1(9) \\
0 \\
9(82) \\
0 \\
0 \\
1(9)\end{array}$ & $\begin{array}{l}0 \\
0 \\
10(83) \\
1(8) \\
1(8) \\
0\end{array}$ & $\begin{array}{l}1(9) \\
1(9) \\
8(73) \\
0 \\
0 \\
1(9)\end{array}$ \\
\hline Mean age (years) & $\min , \max$ & $29(19,44)$ & $30(19,51)$ & $27(20,46)$ & $31(19,54)$ & $27(19,37)$ \\
\hline Mean BMI $\left(\mathrm{kg} / \mathrm{m}^{2}\right)$ & S.D. & $23.9(2.2)$ & $23.7(2.1)$ & $24.7(2.1)$ & $23.0(2.5)$ & $24.0(2.4)$ \\
\hline RAB-M-A002 & & Placebo $(N=7)$ & - & CL184 $20 \mathrm{IU} / \mathrm{kg}(N=12)$ & CL184 $40 \mathrm{IU} / \mathrm{kg}(N=12)$ & $\begin{array}{l}\text { CL184 } 20 \mathrm{IU} / \mathrm{kg}+ \\
\text { PCECV }(N=12)\end{array}$ \\
\hline Sex, $n(\%)$ & $\begin{array}{l}\text { Female } \\
\text { Male }\end{array}$ & $\begin{array}{l}3(43) \\
4(57)\end{array}$ & $\begin{array}{l}- \\
-\end{array}$ & $\begin{array}{l}6(50) \\
6(50)\end{array}$ & $\begin{array}{l}6(50) \\
6(50)\end{array}$ & $\begin{array}{l}6(50) \\
6(50)\end{array}$ \\
\hline Race, $n(\%)$ & Asian & $7(100)$ & - & $12(100)$ & $12(100)$ & $12(100)$ \\
\hline Mean age (years) & $\min , \max$ & $30(22,38)$ & - & $29(21,37)$ & $29(19,39)$ & $29(20,39)$ \\
\hline Mean BMI $\left(\mathrm{kg} / \mathrm{m}^{2}\right)$ & S.D. & $22.7(2.8)$ & - & $21.7(2.5)$ & $22.7(2.9)$ & $24.6(2.5)$ \\
\hline
\end{tabular}

The placebo groups were pooled. BMI: body mass index; min: minimum; max: maximum; S.D.: standard deviation; PCECV: purified chick embryo cell culture vaccine.

neutralization in vitro of a large panel of rabies street viruses from various animal species, as well as in vivo protection in a Syrian hamster rabies challenge model, achieving results comparable to those obtained with HRIG [9-11].

We have performed two phase I studies, one in the USA (RAB-MA001) and one in India (RAB-M-A002), with the primary objective of investigating the safety and tolerability of CL184 in healthy adult subjects. We also collected data on rabies virus neutralizing activity (RVNA) after administration of single doses of CL184 alone or in conjunction with rabies vaccine.

\section{Methods}

\subsection{Subjects}

Female and male healthy adult subjects (RAB-M-A001: $\geq 19$ to $\leq 55$ years; RAB-M-A002: $\geq 18$ to $\leq 55$ years) without previous exposure to rabies vaccine were eligible. Main exclusion criteria were pregnancy, febrile illness, known or suspected impairment of the immune system, intake of immunosuppressive medication, or clinically significant laboratory, cardiac, or physical examination findings.

Written informed consent was obtained from all subjects. The studies were approved by the local independent review boards and were performed according to International Conference on Harmonization guidelines for Good Clinical Practice (ICH-GCP) and the Declaration of Helsinki.

\subsection{Procedures}

RAB-M-A001 was performed in Lincoln, Nebraska, USA (December 2006 to May 2007); RAB-M-A002 was carried out in Mumbai, India (April 2007 to July 2007). Both studies consisted of two parts.

Table 2

Subjects with solicited adverse events

\begin{tabular}{|c|c|c|c|c|c|}
\hline RAB-M-A001 & Placebo $(N=11)$ & CL184 $8 \mathrm{IU} / \mathrm{kg}(N=12)$ & CL184 $20 \mathrm{IU} / \mathrm{kg}(N=11)$ & CL184 $40 \mathrm{IU} / \mathrm{kg}(N=12)$ & $\begin{array}{l}\text { CL184 } 20 \mathrm{IU} / \mathrm{kg}+ \\
\text { PCECV }(N=11)\end{array}$ \\
\hline \multicolumn{6}{|l|}{ Local reactions } \\
\hline Induration & 0 & 0 & 0 & 0 & 0 \\
\hline Pain & $1(9 \%)$ & $1(8 \%)$ & $4(36 \%)$ & $3(25 \%)$ & $1(9 \%)$ \\
\hline Redness & 0 & 0 & 0 & 0 & 0 \\
\hline Swelling & 0 & 0 & 0 & 0 & 0 \\
\hline \multicolumn{6}{|c|}{ Systemic adverse events } \\
\hline Fever & 0 & 0 & 0 & 0 & 0 \\
\hline RAB-M-A002 & Placebo $(N=7)$ & - & $\mathrm{CL} 18420 \mathrm{IU} / \mathrm{kg}(N=12)$ & CL184 $40 \mathrm{IU} / \mathrm{kg}(N=12)$ & $\begin{array}{l}\text { CL184 } 20 \mathrm{IU} / \mathrm{kg}+ \\
\text { PCECV }(N=12)\end{array}$ \\
\hline \multicolumn{6}{|l|}{ Local reactions } \\
\hline Induration & 0 & - & 0 & 0 & 0 \\
\hline Pain & 0 & - & $2(17 \%)$ & 0 & 0 \\
\hline Redness & 0 & - & 0 & 0 & 0 \\
\hline Swelling & 0 & - & 0 & 0 & 0 \\
\hline \multicolumn{6}{|c|}{ Systemic adverse events } \\
\hline Fever & 0 & - & 0 & 0 & 0 \\
\hline
\end{tabular}

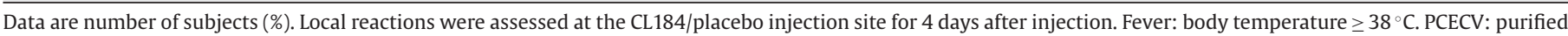
chick embryo cell culture vaccine. 
Table 3

Most frequently reported unsolicited adverse events

\begin{tabular}{|c|c|c|c|c|c|}
\hline RAB-M-A001 & Placebo $(N=11)$ & CL184 $8 \mathrm{IU} / \mathrm{kg}(N=12)$ & CL184 $20 \mathrm{IU} / \mathrm{kg}(N=11)$ & CL184 $40 \mathrm{IU} / \mathrm{kg}(N=12)$ & CL184 $20 \mathrm{IU} / \mathrm{kg}+\mathrm{PCECV}(N=11)$ \\
\hline Subjects with $\geq 1$ adverse event & $9(82)$ & $11(92)$ & $10(91)$ & $9(75)$ & $11(100)$ \\
\hline Abdominal pain upper & 0 & 0 & $1(9)$ & 0 & $2(18)$ \\
\hline AST increased & 0 & $2(17)$ & $1(9)$ & 0 & 0 \\
\hline CK-MB increased & $3(27)$ & $2(17)$ & 0 & 0 & $1(9)$ \\
\hline Cough & $4(36)$ & $2(17)$ & $3(27)$ & $1(8)$ & $2(18)$ \\
\hline Dermatitis contact & 0 & 0 & $2(18)$ & 0 & 0 \\
\hline Dizziness & $1(9)$ & $1(8)$ & $1(9)$ & $1(8)$ & $2(18)$ \\
\hline Fatigue & $1(9)$ & $1(8)$ & 0 & $1(8)$ & $4(36)$ \\
\hline Headache & $2(18)$ & $6(50)$ & $6(55)$ & $2(17)$ & $3(27)$ \\
\hline Injection site bruising & $1(9)$ & $3(25)$ & $1(9)$ & $1(8)$ & $4(36)$ \\
\hline Injection site discomfort $\mathrm{t}^{\mathrm{a}}$ & 0 & 0 & 0 & 0 & $4(36)$ \\
\hline Injection site pain ${ }^{\mathrm{a}}$ & 0 & 0 & 0 & 0 & $2(18)$ \\
\hline Lymphadenopathy & $1(9)$ & $5(42)$ & $3(27)$ & $2(17)$ & 0 \\
\hline Menstruation irregular & 0 & 0 & 0 & $2(17)$ & 0 \\
\hline Nasal congestion & 0 & $2(17)$ & $2(18)$ & $1(8)$ & $4(36)$ \\
\hline Neck pain & $1(9)$ & $2(17)$ & 0 & $1(8)$ & 0 \\
\hline Pain in extremity & 0 & 0 & 0 & 0 & $4(36)$ \\
\hline Pharyngolaryngeal pain & $2(18)$ & $3(25)$ & $1(9)$ & $1(8)$ & $2(18)$ \\
\hline Rhinorrhoea & $2(18)$ & 0 & $2(18)$ & $2(17)$ & 0 \\
\hline Sinus congestion & $2(18)$ & 0 & 0 & 0 & 0 \\
\hline Vomiting & 0 & $1(8)$ & $2(18)$ & $1(8)$ & 0 \\
\hline RAB-M-A002 & Placebo $(N=7)$ & - & CL184 $20 \mathrm{IU} / \mathrm{kg}(N=12)$ & $\mathrm{CL} 18440 \mathrm{IU} / \mathrm{kg}(N=12)$ & CL184 $20 \mathrm{IU} / \mathrm{kg}+\operatorname{PCECV}(N=12)$ \\
\hline Subjects with $\geq 1$ adverse event & $2(29)$ & - & $4(33)$ & $8(67)$ & $3(25)$ \\
\hline CK-MB increased & 0 & - & 0 & $1(8)$ & $2(17)$ \\
\hline Lipase increased & 0 & - & 0 & $2(17)$ & 0 \\
\hline Vomiting & 0 & - & 0 & $2(17)$ & 0 \\
\hline
\end{tabular}

Data are number of subjects (\%). Adverse events occurring in at least two subjects in a group are shown. PCECV: purified chick embryo cell culture vaccine.

a At the vaccine injection site.

Part 1 had a double blind, placebo-controlled, dose-escalation design. Subjects were assigned to single doses of CL184 $(8 \mathrm{IU} / \mathrm{kg}$, $20 \mathrm{IU} / \mathrm{kg}$, or $40 \mathrm{IU} / \mathrm{kg}$ in $\mathrm{RAB}-\mathrm{M}-\mathrm{A} 001 ; 20 \mathrm{IU} / \mathrm{kg}$ or $40 \mathrm{IU} / \mathrm{kg}$ in $\mathrm{RAB}-\mathrm{M}-\mathrm{A002}$ ) or placebo in a 3:1 ratio according to a computergenerated block randomization list. Placebo consisted of the CL184 formulation buffer with the identical excipient composition but lacking the active ingredients CR57 and CR4098. In RAB-M-A001, the first four subjects at each dose level were dosed at least $2 \mathrm{~h}$ apart; the next subjects were dosed at least 10 days later. In both studies, day 7 data for each dosage group were examined to exclude safety concerns before a higher dose was given in the next group.

Part 2 had an open-label, uncontrolled design, in which CL184 $20 \mathrm{IU} / \mathrm{kg}$ was given on day 0 in a simulated PEP setting, in conjunction with purified chick embryo cell culture (PCEC) rabies vaccine administered intramuscularly according to the Essen regimen (days $0,3,7,14,28)[12]$.

CL184 contained $1000 \mathrm{IU} / \mathrm{mL}$ of a $1: 1$ equipotent mixture of the mAbs CR57 and CR4098. Single doses were injected into the lateral thigh muscle. One millilitre of rabies vaccine (RAB-M-A001: RabAvert $^{\mathrm{TM}}$, Lot No. 411011 potency 9.7 IU/dose and Lot No. 406011 potency 7.1 IU/dose; RAB-M-A002: Rabipur ${ }^{\mathrm{TM}}$, Lot No. 1415 potency $9.05 \mathrm{IU} /$ dose) was injected into the deltoid muscle (contralateral to CL184/placebo).

The subjects arrived at the clinical centre on the day before dosing and were kept under observation for $96 \mathrm{~h}$ (RAB-M-A001, first in human administration) or $24 \mathrm{~h}$ (RAB-M-A002) after dosing. In both study parts, blood samples were collected before dosing on day 0 , and on days $1,2,3,7,14,21,28$, and 42 .

Safety assessments included physical examination, electrocardiogram, blood pressure and heart rate monitoring, and routine laboratory tests. Human anti-human antibodies (HAHAs) were measured using a BIACore ${ }^{\circledR}$ assay at BioAnaLab Ltd., Oxford, UK. Unsolicited adverse events were recorded throughout the study. In addition, the subjects were asked if they had experienced induration, pain, redness, or swelling at the CL184/placebo injec- tion site and body temperature was documented for 4 days after CL184/placebo administration (solicited adverse events).

RVNA was measured with the rapid fluorescent focus inhibition test (RFFIT) [13] at Kansas State Veterinary Diagnostic Laboratory, Manhattan, USA.

The studies were registered as ISRCTN (ISRCTN18660493 and ISRCTN12693237).

\subsection{Statistical analysis}

The primary objective of both studies was to investigate safety; no inferential statistics were performed. Safety was analysed descriptively for all subjects who had received CL184/placebo.

For calculation of geometric mean RVNA, values below the lower limit of quantitation of $0.05 \mathrm{IU} / \mathrm{mL}$ were set to half of the limit. Data from subjects with detectable RVNA at baseline (pre-dose) were excluded from the RVNA analysis (three subjects in RAB-M-A001 and four subjects in RAB-M-A002).

\section{Results}

RAB-M-A001 included 57 subjects, of whom five did not complete the study because of non-compliance or withdrawal of consent. Of the 44 subjects enrolled in RAB-M-A002, one was withdrawn before administration of placebo due to non-compliance. RAB-M-A001 (USA) included mainly Caucasians while all subjects participating in RAB-M-A002 (India) were Asian. Table 1 summarizes demographic characteristics. Demographic characteristics were well balanced for all groups in RAB-M-A002; in RAB-M-A001, two CL184 dosage groups differed with respect to sex distribution.

Subjects in both studies reported only a few local reactions (Table 2) during the 4 days after CL184 injection. Pain at the injection site was noted by one to four subjects in each group in RAB-M-A001 and by two subjects in the CL184 $20 \mathrm{IU} / \mathrm{kg}$ group in RAB-M-A002. There were no occurrences of induration, red- 
RAB-M-A001
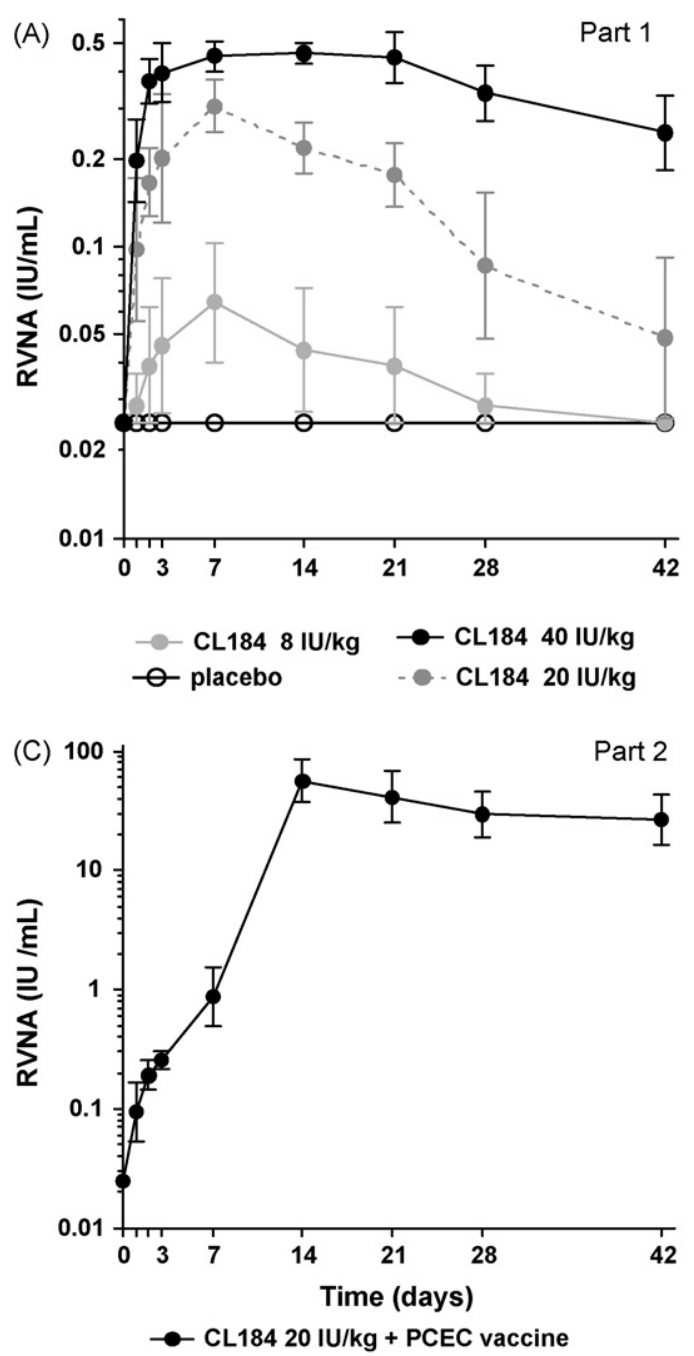

RAB-M-A002

(B)
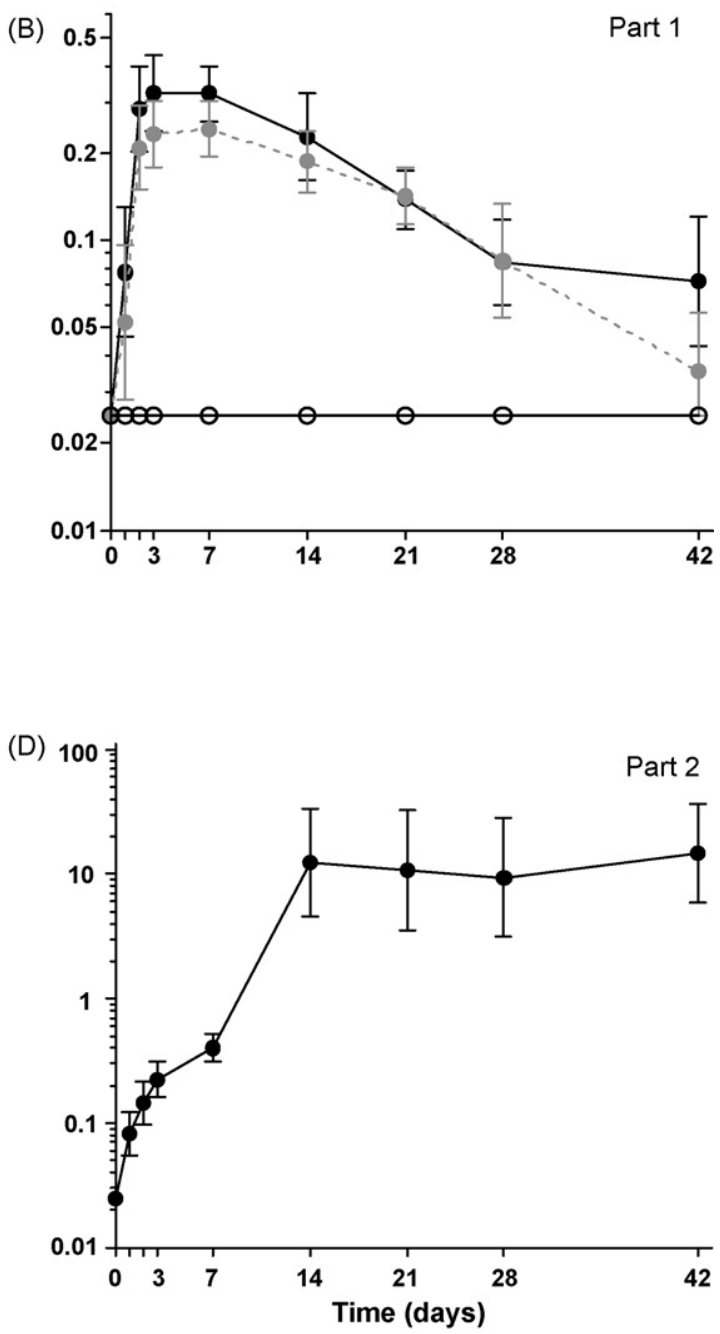

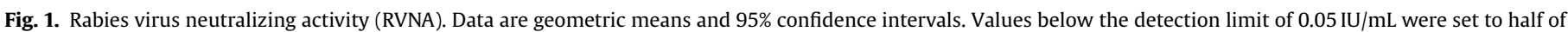
the limit. Subjects with detectable RVNA at baseline were excluded from the analysis.

ness, or swelling at the injection site, and no subjects developed fever.

In RAB-M-A001, most subjects receiving CL184 without vaccination reported unsolicited adverse events (Table 3 ); the incidence rates were similar to those after placebo administration and no dose-relationship was observed. When CL184 was administered in conjunction with rabies vaccine, all subjects reported adverse events. A different pattern of adverse events was observed in RAB$\mathrm{M}-\mathrm{A} 002$, where incidence rates were low (less or equal to one-third of subjects) in all but the CL184 $40 \mathrm{IU} / \mathrm{kg}$ group (two-thirds of subjects). Adverse events affecting at least two subjects in a group in both studies were increased creatinine kinase muscle-brain isoenzyme (CK-MB, indicative of cardiac muscle involvement) levels and vomiting. The elevation of CK-MB was not accompanied by clinical signs or symptoms, and both of these events appeared to be unrelated to CL184.

Serious adverse events were reported by two subjects participating in RAB-M-A001, both in the CL184 $40 \mathrm{IU} / \mathrm{kg}$ group. One subject was hospitalized for mild back pain and muscle strain due to a motor vehicle accident; the other experienced suicidal ideation and worsening of an undisclosed pre-existing post-traumatic stress disorder upon stopping his medications (without consulting a physician) in order to participate in the study. Both events were assessed by the investigator as being mild and unrelated to CL184 administration. In RAB-M-A002, one case of hepatitis E infection was reported as a serious adverse event in a subject receiving CL184 $40 \mathrm{IU} / \mathrm{kg}$. This event was of severe intensity and was assessed as being unrelated to treatment

There were no discontinuations due to adverse events. Most adverse events in both studies were of mild intensity. Severe but non-serious events after CL184 administration were increased CK, increased CK-MB, and increased lipase. These events were all assessed by the investigator as being unrelated to CL184.

Routine safety laboratory tests revealed elevations of clinical relevance in Aspartate Transaminase (AST), CK-MB, or lipase in several subjects receiving CL184 or placebo; no treatment- or dose-related trends were observed. The other safety assessments found no indications of hepatic, cardiac, or pancreatic disorders.

Treatment-emergent CL184-specific HAHAs were not detected in any subjects.

RVNA was consistently detectable by RFFIT from day 1 up to day 21 after administration of CL184 $20 \mathrm{IU} / \mathrm{kg}$ or $40 \mathrm{IU} / \mathrm{kg}$, but not CL184 $8 \mathrm{IU} / \mathrm{kg}$. The dose-escalation parts of the studies showed dose- 
dependent increases in geometric mean RVNA (Fig. 1 panels A and B). In RAB-M-A001, peak levels were reached by day 7 after administration of CL184 $8 \mathrm{IU} / \mathrm{kg}(0.06 \mathrm{IU} / \mathrm{mL})$ or $20 \mathrm{IU} / \mathrm{kg}(0.30 \mathrm{IU} / \mathrm{mL})$ and by day 14 after administration of CL184 $40 \mathrm{IU} / \mathrm{kg}(0.46 \mathrm{IU} / \mathrm{mL})$. In RAB-M-A002, the highest levels were observed on day 3 (CL184 $40 \mathrm{IU} / \mathrm{kg}$ : $0.32 \mathrm{IU} / \mathrm{kg}$ ) and day 7 (CL184 $20 \mathrm{IU} / \mathrm{kg}: 0.24 \mathrm{IU} / \mathrm{kg}$ ).

When a single dose of CL184 $20 \mathrm{IU} / \mathrm{kg}$ (day 0) was administered in a simulated PEP setting together with rabies vaccination (days 0 , $3,7,14$ and 28), RVNA levels were comparable to those after administration of CL184 $20 \mathrm{IU} / \mathrm{kg}$ alone up to day 3 (Fig. 1 panels C and D). A steep increase in RVNA levels was seen from day 7 to day 14 in both studies. The peak value was lower in RAB-M-A002 $(12.38 \mathrm{IU} / \mathrm{mL})$ than in RAB-M-A001 (56.43 IU/mL). After day 14, RVNA levels decreased slightly until day 42 in RAB-M-A001, but showed a slight increase towards the end of the study in RAB-M-A002. From day 14 onwards, all subjects in both studies had RVNA levels above $0.5 \mathrm{IU} / \mathrm{mL}$, the level considered adequate according to WHO [1]. Four out of 11 (RAB-M-A001) and three out of ten subjects (RAB-MA002) had RVNA levels exceeding the threshold as early as day 7.

\section{Discussion}

Although effective PEP regimens are established, human death rates due to rabies infection remain unacceptably high [1]. True PEP failures are rare, but many patients exposed to rabies do not receive adequate medical care [7]. Improper wound cleaning or a delayed onset of PEP put patients at risk of death. The same is true if incomplete PEP regimens are used, which happens frequently because of unavailability of proper quality biologicals. An Indian survey showed that in 2003 only $2.1 \%$ of patients with severe rabies exposure received RIG [14]. It is well known that even accelerated vaccination schedules do not eliminate the need for RIG after severe exposure [5].

Preclinical data have indicated that the CL184 mAb cocktail is a promising candidate for use as an alternative to HRIG and ERIG in PEP [9]. In this publication, we present the first clinical data for CL184.

The local tolerability of CL184 was very good, with less than $40 \%$ of subjects in each dosage group reporting pain at the injection site. In the US study, some injection site bruising was reported. However, other typical local reactions were not seen at all. Overall, fewer local reactions were observed than in a similar study investigating intramuscular administration of HRIG in healthy subjects [15]. Because of its high concentration, CL184 can be injected in lower volumes than HRIG or ERIG, which might contribute to better local tolerability. The lower volumes required will also facilitate infiltration of the complete required dose into the wound, which is critical for treatment success [7].

Fever was not reported in any subject in either study. General systemic reactions observed included headache, dizziness, fatigue, and vomiting. Incidence rates for these symptoms in RAB-M-A001 (USA) were similar or lower than those seen in a US study in which healthy adults received intramuscular HRIG in combination with rabies vaccine [15]. In an observational study involving German healthcare workers, the most frequent adverse events reported after PEP with HRIG and rabies vaccine were tiredness, malaise, headache, and dizziness at rates roughly comparable to those observed in RAB-M-A001 after simulated PEP with CL184 and rabies vaccine [16]. Based on the persistence of symptoms during PEP, the investigators concluded that strong headache, tiredness, dizziness, and paraesthesia might be symptoms specific to rabies vaccination. In RAB-M-A001, headache was more frequent after administration of CL184 alone than after administration in conjunction with rabies vaccine, although no dose-relationship was apparent; in RAB-M-A002, only one subject in the CL184 $40 \mathrm{IU} / \mathrm{mL}$ group reported headache.

Much lower incidence rates of unsolicited adverse events were seen in RAB-M-A002 than in RAB-M-A001. This is in line with the lower rates observed in other studies performed in Asia [17-19] and can most likely be attributed to cultural differences in the reporting of adverse effects.

Routine safety laboratory tests revealed elevations of clinical relevance in AST, CK-MB or lipase levels. We assume that these findings were unspecific, because no other abnormalities indicative of hepatic, cardiac, or pancreatic disorders were apparent. CK-MB levels have been shown to be highly variable in healthy subjects as elevated CK-MB levels can be found; unrelated to myocardial cause, in asymptomatic subjects with elevated total CK. In our studies, one asymptomatic subject had an extremely elevated CK-MB but was found to have a troponin I level of zero, indicating the absence of cardiac aetiology.

Administration of recombinant therapeutic proteins, even those of entirely human origin, could potentially evoke an antibody response [20]. However, HAHAs specific for CL184 were not detected in either study. An immune response that could interfere with the activity of the CL184 antibody cocktail is therefore unlikely.

The efficacy of CL184 administered in PEP can only be fully demonstrated in patients exposed to rabies and will depend on the ability of the mAbs to neutralize rabies virus locally in the wound $[12,21]$. In our phase I studies, we measured serum RVNA as a surrogate marker of efficacy. The dose-escalation trials showed a clear dose response, with peak RVNA levels in the range of those observed after intramuscular administration of ERIG or HRIG [15,22-24]. Intramuscular administration of HRIG at $20 \mathrm{IU} / \mathrm{kg}$ given without rabies vaccine was reported to result in maximum serum antibody concentrations around day 3-14 of approximately $0.1 \mathrm{IU} / \mathrm{mL}$ with measurable titers in 56\% of the subjects at days 3 and 7 [15]. CL184 administration at $20 \mathrm{IU} / \mathrm{kg}$ resulted in similar profiles of neutralizing activity with detectable levels in 96 and $100 \%$ of the subjects at days 3 and 7 and maximal titers at day 7 of $0.30 \mathrm{IU} / \mathrm{mL}$ in RAB-MA001 and $0.24 \mathrm{IU} / \mathrm{mL}$ in RAB-M-A002, respectively.

When CL184 was administered in conjunction with rabies vaccine, all subjects in both studies had RVNA levels considered to be adequate $(>0.5 \mathrm{IU} / \mathrm{mL}$ ) from day 14 onwards, and these levels were achieved in 7 of 21 (33\%) subjects as early as day 7. If the threshold was set to include levels $\geq 0.5 \mathrm{IU} / \mathrm{mL}$, as done in studies with other rabies vaccines than RabAvert $^{\mathrm{TM}} /$ Rabipur $^{\mathrm{TM}}$, this proportion is increased to 14 out of 21 (67\%) subjects on day 7. These results are very comparable to those obtained with current PEP regimens whereby $13-20 \%$ of subjects receiving human diploid cell vaccine (HDCV) plus HRIG seroconverted $(\geq 0.5 \mathrm{IU} / \mathrm{mL})$ at day 7 and $100 \%$ of subjects seroconverted at day 14 [15].

Our studies further confirmed the importance of immediate administration of RIG to inhibit viral spread during the first 7-14 days, before there is sufficient immune response to the vaccine. Overall, geometric mean RVNA levels in RAB-M-A002 were lower than in RAB-M-A001. This might be related to the different levels of physical activity (the period of confinement without strenuous activity was longer in RAB-M-A001), slight differences in the vaccines that were used (RabAvert ${ }^{\mathrm{TM}}$ vs. Rabipur ${ }^{\mathrm{TM}}$ ), or ethnic and environmental factors.

Results from some previous studies have indicated that RIGs can potentially interfere with the immune response to rabies vaccination [23,25-27]. We did not specifically investigate a potential interference between CL184 and rabies vaccine in our studies. If there was any interaction, this was not clinically relevant, as evidenced by the high RVNA levels induced by simulated PEP with CL184 and rabies vaccine. 
In conclusion, our studies confirmed that CL184 may offer a safe and effective alternative for ERIG or HRIG. CL184 is a well-defined cocktail of two fully human mAbs and can be produced in large quantities in the extensively characterized and well-established PER.C6 ${ }^{\circledR}$ human cell line. Its successful development would help to ensure supply of life-saving biologicals to people exposed to rabies and - coupled with educational measures and efforts to eliminate canine rabies - could substantially reduce the high death toll associated with this disease.

\section{Acknowledgments}

This study was funded by Crucell N.V. We thank the subjects for participating in this trial; the study nurses and other staff members for contributing in many ways of this study. We are indebted to Edna Venneker and Peter Ryle for their pivotal contributions. We thank Marlen Schoenfeld and Ruben Ibanez for their operational support in facilitating the studies. Martina Rauscher and Andrea Dingemans are acknowledged for their critical review of the manuscript.

\section{References}

[1] Rabies vaccines. WHO position paper. Wkly Epidemiol Rec 2007;82(49/50): 425-35.

[2] Dodet B. An important date in rabies history. Vaccine 2007;25(52):8647-50.

[3] Rupprecht CE, Hanlon CA, Hemachudha T. Rabies re-examined. Lancet Infect Dis 2002;2(6):327-43.

[4] Rupprecht CE, Gibbons RV. Clinical practice. Prophylaxis against rabies. N Engl J Med 2004;351(25):2626-35.

[5] Wilde H, Khawplod P, Hemachudha T, Sitprija V. Postexposure treatment of rabies infection: can it be done without immunoglobulin? Clin Infect Dis 2002;34(4):477-80

[6] Dodet B. Preventing the incurable: Asian rabies experts advocate rabies control. Vaccine 2006:24(16):3045-9.

[7] Wilde H. Failures of post-exposure rabies prophylaxis. Vaccine 2007;25(44): 7605-9.

[8] WHO. WHO consultation on a rabies monoclonal antibody cocktail for rabies post exposure treatment. Geneva: WHO, 23-24; May 2002 http://www.who.int/rabies/vaccines/en/mabs_final_report.pdf 2002.

[9] Bakker AB, Marissen WE, Kramer RA, Rice AB, Weldon WC, Niezgoda M, et al. Novel human monoclonal antibody combination effectively neutralizing natural rabies virus variants and individual in vitro escape mutants. J Virol 2005;79(14):9062-8.

[10] Marissen WE, Kramer RA, Rice A, Weldon WC, Niezgoda M, Faber M, et al. Novel rabies virus-neutralizing epitope recognized by human monoclonal antibody: fine mapping and escape mutant analysis. J Virol 2005;79(8):4672-8.

[11] Goudsmit J, Marissen WE, Weldon WC, Niezgoda M, Hanlon CA, Rice AB, et al. Comparison of an anti-rabies human monoclonal antibody combination with human polyclonal anti-rabies immune globulin. J Infect Dis 2006;193(6):796-801.
[12] Current WHO guide for rabies pre- and post-exposure treatment in humans. WHO; 2002.

[13] Smith JS, Yader PA, Baer GM. A rapid fluorescent focus inhibition test (RFFIT) for determining rabies virus-neutralizing antibody. In: Meslin F-X, Kaplan MM, Koprowski H, editors. Laboratory techniques in rabies. 4th ed. Geneva, Switzerland: World Health Organization; 1996. p. 181-92.

[14] Sudarshan MK, Madhusudana SN, Mahendra BJ, Rao NS, Ashwath Narayana $\mathrm{DH}$, Abdul RS, et al. Assessing the burden of human rabies in India: results of a national multi-center epidemiological survey. Int J Infect Dis 2007;11(1): 29-35.

[15] Lang J, Gravenstein S, Briggs D, Miller B, Froeschle J, Dukes C, et al. Evaluation of the safety and immunogenicity of a new, heat-treated human rabies immune globulin using a sham, post-exposure prophylaxis of rabies. Biologicals 1998;26(1):7-15.

[16] Mattner F, Bitz F, Goedecke M, Viertel A, Kuhn S, Gastmeier P, et al. Adverse effects of rabies pre- and postexposure prophylaxis in 290 health-care-workers exposed to a rabies infected organ donor or transplant recipients. Infection 2007;35(4):219-24.

[17] Suwansrinon K, Jaijaroensup W, Daviratanasilpa S, Sriaroon C, Wilde H, Sitprija V. Adverse reactions to human rabies immune globulin manufactured by the Thai Red Cross Society. Vaccine 2005;23(11):1324-5.

[18] Quiambao BP, Lang J, Vital S, Montalban CG, Le MV, Wood SC et al. Immunogenicity and effectiveness of post-exposure rabies prophylaxis with a new chromatographically purified Vero-cell rabies vaccine (CPRV): a two-stage randomised clinical trial in the Philippines. Acta Trop 2000;75(1):39-52.

[19] Sehgal S, Bhattacharya D, Bhardwaj M. Ten year longitudinal study of efficacy and safety of purified chick embryo cell vaccine for pre- and post-exposure prophylaxis of rabies in Indian population. J Commun Dis 1995;27(1):36-43.

[20] Ritter G, Cohen LS, Williams Jr C, Richards EC, Old LJ, Welt S. Serological analysis of human anti-human antibody responses in colon cancer patients treated with repeated doses of humanized monoclonal antibody A33. Cancer Res 2001;61(18):6851-9.

[21] Human rabies prevention-United States. Recommendations of the Advisory Committee on Immunization Practices (ACIP). MMWR Recomm Rep 1999;48(RR-1):1-21.

[22] Lang J, Attanath P, Quiambao B, Singhasivanon V, Chanthavanich P, Montalban $C$, et al. Evaluation of the safety, immunogenicity, and pharmacokinetic profile of a new, highly purified, heat-treated equine rabies immunoglobulin, administered either alone or in association with a purified, Vero-cell rabies vaccine. Acta Trop 1998;70(3):317-33.

[23] Mertz GJ, Nelson KE, Vithayasai V, Makornkawkeyoon S, Rosanoff EI, Tint H, et al. Antibody responses to human diploid cell vaccine for rabies with and without human rabies immune globulin. J Infect Dis 1982;145(5):720-7.

[24] Nicholson KG, Turner GS. Studies with human diploid cell strain rabies vaccine and human antirabies immunoglobulin in man. Dev Biol Stand 1978;40:115-20.

[25] Loofbourow JC, Cabasso VJ, Roby RE, Anuskiewicz W. Rabies immune globulin (human). Clinical trials and dose determination. JAMA 1971;217(13):1825-31.

[26] Aoki FY, Rubin ME, Friesen AD, Bowman JM, Saunders JR. Intravenous human rabies immunoglobulin for post-exposure prophylaxis: serum rabies neutralizing antibody concentrations and side-effects. J Biol Stand 1989;17(1): 91-104.

[27] Lang J, Simanjuntak GH, Soerjosembodo S, Koesharyono C. Suppressant effect of human or equine rabies immunoglobulins on the immunogenicity of postexposure rabies vaccination under the 2-1-1 regimen: a field trial in Indonesia. MAS054 Clinical Investigator Group. Bull World Health Org 1998;76(5): 491-5. 